\title{
Dose Compact Job Demand Lead to Employee Delay? The Mediating Effect of Job Burnout and The Moderating Effect of Perceived Control of Time.
}

Tzu-Ting Lin

Department of Psychology, National Chengchi University

\section{Why conduct this study?}

Considering the fast-paced and compact working style of contemporary life, this study explored the effect of time-related job demands on work procrastination, and it further explored the mediating role of job burnout as well as the moderating role of perceived control of time based on the job demands-resources theoretical model (JD-R model).

\section{Main research contribution}

By integrating the concept of temporal personal resources with that of time-related job demands, a temporal perspective was adopted and applied with a moderated mediation model to comprehensively explore the buffer effect of perceived control of time on the health impairment process described by the temporal JD-R model.

\section{Method}

\section{$\checkmark$ SAMPLE AND PROCEDURES}

- This study collected 221 sets of valid dyadic questionnaires of supervisors and their single pairing subordinates.

$\downarrow$ Of those employees, $52.5 \%$ were males, average age was 37.35 , $79.1 \%$ had a master's degree, and average tenure was 7.11 years.

\section{$\diamond$ MEASURES}

- Time-related job demands was adapted from Schriber and Gutek (1987), 3 items, $\alpha=.80$.

$\checkmark$ Job burnout was applied Maslach Burnout Inventory-General

Survey (Maslach, Jackson, \& Leiter, 1996), 5 items, $\alpha=.87$.

$\checkmark$ Perceived control of time was applied Macana (1994), 5 items, $\alpha$

$=.93$.

$\checkmark$ Work path was adopted from Gevers, Rutte, and van Eerde (2006), 1 items.

$\diamond$ Control variables. Employee's sex, age, and tenure.
Research framework and results

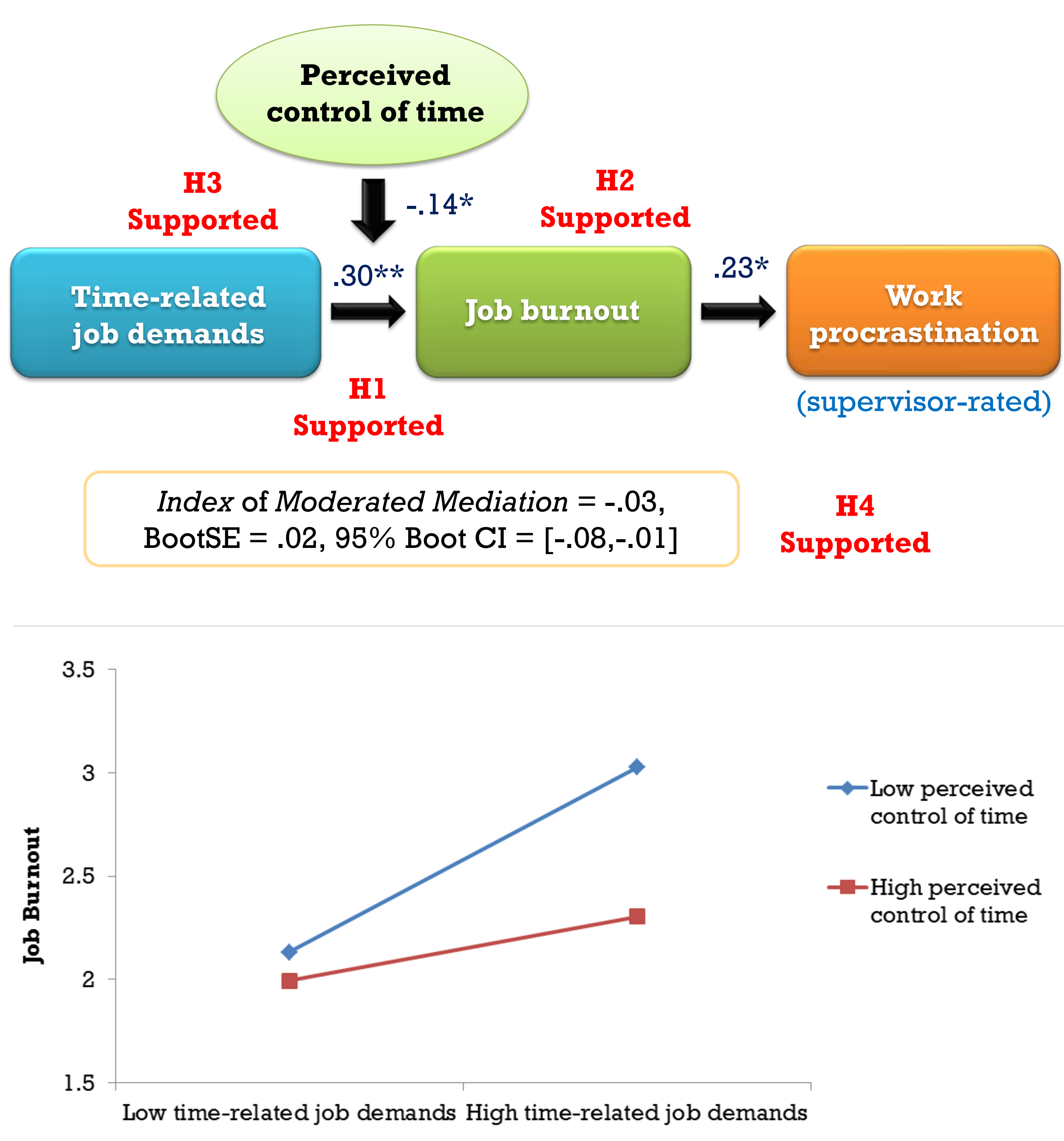

